OPEN ACCESS

Edited by: Ottavia Giuffrè,

University of Messina, Italy

Reviewed by:

Carlo Siciliano,

University of Calabria, Italy

Rita Giovannetti,

University of Camerino, Italy

*Correspondence:

Stefano Materaz

stefano.materazzi@uniroma1.it

Specialty section:

This article was submitted to

Analytical Chemistry,

a section of the journal

Frontiers in Chemistry

Received: 06 October 2020

Accepted: 27 October 2020

Published: 01 December 2020

Citation:

Risoluti R, Gullifa G and Materazi S (2020) Assessing the Quality of Milk Using a Multicomponent Analytical Platform MicroNIR/Chemometric

\section{Assessing the Quality of Milk Using a Multicomponent Analytical Platform MicroNIR/Chemometric}

\author{
Roberta Risoluti, Giuseppina Gullifa and Stefano Materazi* \\ Department of Chemistry, Sapienza University of Rome, Rome, Italy
}

In this work, an innovative screening platform based on MicroNIR and chemometrics is proposed for the on-site and contactless monitoring of the quality of milk using simultaneous multicomponent analysis. The novelty of this completely automated tool consists of a miniaturized NIR spectrometer operating in a wireless mode that allows samples to be processed in a rapid and accurate way and to obtain in a single click a comprehensive characterization of the chemical composition of milk. To optimize the platform, milk specimens with different origins and compositions were considered and prediction models were developed by chemometric analysis of the NIR spectra using Partial Least Square regression algorithms. Once calibrated, the platform was used to predict samples acquired in the market and validation was performed by comparing results of the novel platform with those obtained from the chromatographic analysis. Results demonstrated the ability of the platform to differentiate milk as a function of the distribution of fatty acids, providing a rapid and non-destructive method to assess the quality of milk and to avoid food adulteration.

Keywords: milk, microNIR, chemometrics, quality control, new methods, multiparametric analysis

\section{INTRODUCTION}

Milk is one of the most investigated food matrices worldwide and the analyses usually aim at estimating its chemical composition, in order to evaluate its quality (Hambraeus, 1984; Cunsolo et al., 2017). In particular, the quality of milk is mainly related to the fatty acid content (Napoli et al., 2007; Zhou et al., 2014), as well as the amount of lactose, proteins, and vitamin D. The increasing demand from consumers for innovative dietary products has globally led to an increasing request of procedures and methods to detect adulteration of food matrices (Cossignani et al., 2011; Materazzi et al., 2012). In particular, adulteration of milk mainly consists of the addition or the illegal use of additives or molecules, including melamine (Balabin and Smirnov, 2011), sugars (Kamboj et al., 2020), urea (Mabood et al., 2019), and formalin (Saha and Thangavel, 2018).

Therefore, a method which could assess the quality of a food product and perform a multicomponent characterization at the first level test represents an important issue when dealing 
with the monitoring of food quality or human health. For this reason, innovative screening systems, able to rapidly process samples without requiring any pretreatment or clean up, in a non-destructive way, are becoming more and more recommended (Dunn et al., 2011; Risoluti et al., 2016, 2019a,b,c; D'Elia et al., 2018). Reference analytical procedures for milk analyses usually require chromatographic techniques, such as High Performance Liquid Chromatography associated to Mass Spectrometry (HPLC-MS) (Chotyakul et al., 2014; Aiello et al., 2015; Rocchetti et al., 2020), Gas Chromatography coupled to Mass Spectrometry (GC-MS) (Marchetti et al., 2002; Materazzi and Risoluti, 2014; Teng et al., 2017), and Nuclear Magnetic Resonance (NMR) (Garcia et al., 2012; Crea et al., 2014; Santos et al., 2016; Aiello et al., 2018).

Spectroscopic techniques are widely recognized as solventfree, fast, and easy-to-use tools to perform the chemical investigation of different matrices without destroying samples (Oliveri et al., 2011; Materazzi et al., 2017a,b; Véstia et al., 2019). In particular, NIR spectroscopy associated with chemometric analysis proved its high potential in multicomponent analyses, at low costs and without requiring the supervision of specialized personnel (Kurdziel et al., 2003; Migliorati et al., 2013; Kordi et al., 2017; Materazzi et al., 2017c; Mees et al., 2018). NIR spectroscopy has been largely proposed for the investigation of milk with the aim of providing innovative and rapid methods for the detection of lactose, proteins, carotenoids, and fatty acid contents (Jankovskà and Šustovà, 2003; Numthuam et al., 2017; Risoluti et al., 2017; Wang et al., 2019; Soulat et al., 2020). In addition, NIR spectroscopy allows users moving out of the laboratory and performing prediction of analytes in complex matrices (Navarra et al., 2003; Bretti et al., 2013; Paiva et al., 2015; Basri et al., 2017; da Silva et al., 2017; Modrono et al., 2017; Risoluti and Materazzi, 2018; Risoluti et al., 2018a,b) by means of portable instruments that directly analyze milk and provide the results (De Angelis Curtis et al., 2008; Bian et al., 2017; Ferreira de Lima et al., 2018). Despite these instruments permitting the transfer of validated methods directly on site, they do not provide a tool enabling consumers to rapidly check the product by itself for application to real situations.

Based on these considerations, this work proposes a novel method based on a miniaturized spectrometer, the MicroNIR OnSite, for the multicomponent analysis of milk for food quality control. This platform uses chemometric tools to develop models of prediction that, once validated, provide the fast and accurate characterization of milk specimens in a "click," using a contactless and wireless miniaturized instrument that can be installed on a consumer's smartphone.

\section{MATERIALS AND METHODS}

\section{Experimental}

\section{Analytical Workflow}

Milk specimens were provided by different producers in Italy and included cow, goat, and donkey milk, as well as rice milk. In addition, samples were selected considering their different amounts of fats and treatments and considering whole, skimmed, and low-fat milk and UHT milk. For each sample, about $1 \mathrm{ml}$
TABLE 1 | List of the investigated milk specimens.

\begin{tabular}{|c|c|c|}
\hline Samples & $\begin{array}{l}\text { Number of } \\
\text { spectra }\end{array}$ & $\begin{array}{c}\text { Fats } \\
(g / 100 \mathrm{~mL})\end{array}$ \\
\hline \multicolumn{3}{|l|}{ Whole Milk } \\
\hline Goat Milk_Fresh Whole Milk_Amalattea & 100 & 3.9 \\
\hline Goat Milk_Latte UHT Intero-Amalattea & 150 & 3.9 \\
\hline Cow Milk_Fresh Whole Milk_Centrale del Latte & 100 & 3.6 \\
\hline $\begin{array}{l}\text { Cow Milk-Fresh Organic Whole Milk-Centrale } \\
\text { del Latte }\end{array}$ & 100 & 3.6 \\
\hline \multicolumn{3}{|l|}{ Semi Skimmed Milk } \\
\hline Goat Milk-Semi Skimmed UHT Milk-Amalattea & 150 & 1.6 \\
\hline $\begin{array}{l}\text { Cow Milk_Fresh Semi Skimmed Milk_Centrale } \\
\text { del Latte }\end{array}$ & 150 & 1.6 \\
\hline $\begin{array}{l}\text { Cow Milk-Semi Skimmed Organic UHT } \\
\text { Milk-Granarolo }\end{array}$ & 150 & 1.6 \\
\hline $\begin{array}{l}\text { Cow Milk-Semi Skimmed UHT Milk-Zymil } \\
\text { Parmalat }\end{array}$ & 150 & 1 \\
\hline $\begin{array}{l}\text { Cow Milk-Semi Skimmed Organic UHT } \\
\text { Milk_Zymil Parmalat }\end{array}$ & 150 & 1 \\
\hline $\begin{array}{l}\text { Cow Milk-Microfiltered Semi Skimmed UHT } \\
\text { Milk-Selex }\end{array}$ & 150 & 1 \\
\hline Cow Milk_Semi Skimmed UHT Milk_Accadì & 50 & 1 \\
\hline \multicolumn{3}{|l|}{ Skimmed Milk } \\
\hline $\begin{array}{l}\text { Cow Milk-Fresh Skimmed Milk-Centrale del } \\
\text { Latte }\end{array}$ & 50 & $<0.5$ \\
\hline Cow Milk-Skimmed UHT Milk_Parmalat & 150 & $<0.5$ \\
\hline $\begin{array}{l}\text { Cow Milk-Skimmed UHT Milk-Centrale del } \\
\text { Latte }\end{array}$ & 100 & 0.1 \\
\hline Cow Milk_Skimmed UHT Milk-Zymil Parmalat & 150 & 0.1 \\
\hline Cow Milk_Skimmed UHT Milk_Accadì & 100 & 0.1 \\
\hline \multicolumn{3}{|l|}{ Rice Milk } \\
\hline UHT Rice Milk - Vital Nature & 100 & 1 \\
\hline \multicolumn{3}{|l|}{ Donkey Milk } \\
\hline UHT Donkey Milk & 50 & \\
\hline
\end{tabular}

of milk was directly analyzed by the MicroNIR equipped with a special accessory for liquids; no sample pre-treatment was necessary. A detailed list of the investigated samples is reported in Table 1.

Chemometric analysis was performed by Principal Component Analysis in order to evaluate correlations among measurements and to provide a rapid tool able to identify the adulteration of milk as a function of the fats contents.

Calibration and validation of the platform was obtained by dividing the data set of measurements in the training set and evaluation set, while the prediction of real samples was achieved by processing 17 additional samples not previously included in the dataset and thus processed as an independent batch. This step is strictly required, in order to guarantee the results are not bath-dependent and to ensure reproducibility and effectiveness of the platform.

\section{MicroNIR On-Site Spectrometer}

The MicroNIR On-Site is a portable spectrometer device operating in the NIR region of the spectrum $(900-1,700 \mathrm{~nm})$ 


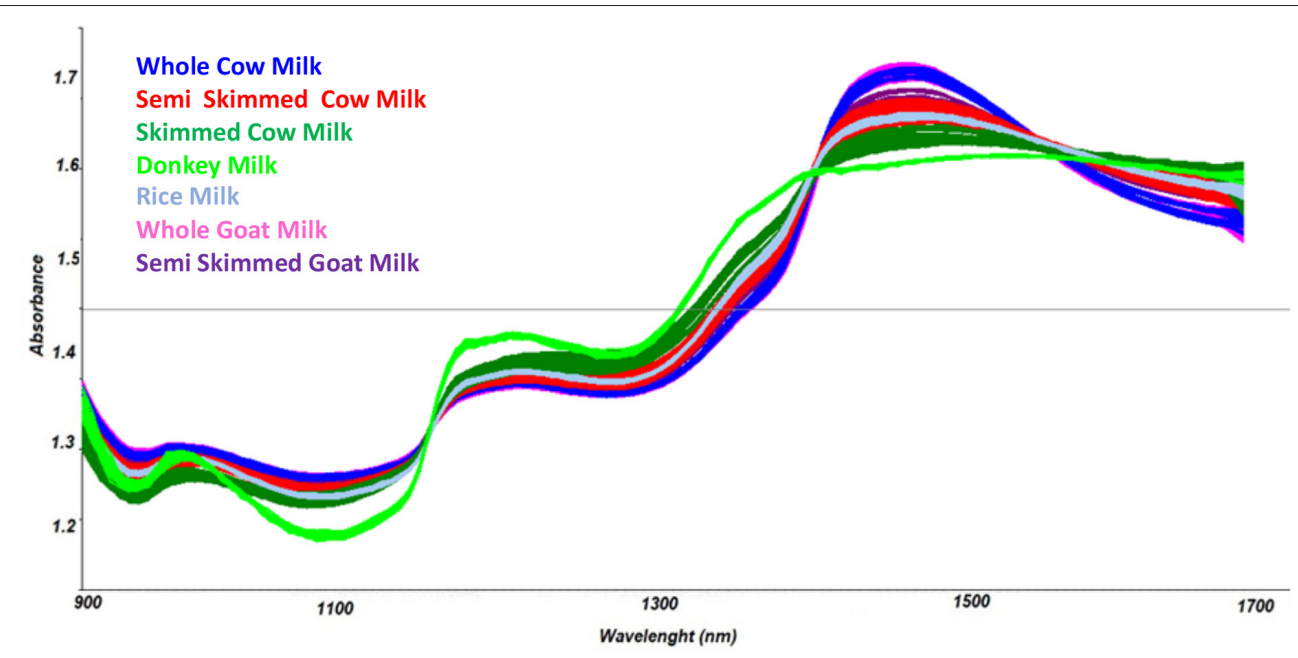

FIGURE 1 | Collected spectra of milk specimens.

and distributed by Viavi Solutions (JDSU Corporation, Milpitas, USA). It is specifically the latest version of the ultracompact MicroNIR from Viavi and represents the real update in the field of the miniaturized device, moving out of the laboratory. In fact, it is provided by two different pieces of software (JDSU Corporation, Milpitas, USA): the first is the MicroNIR Pro software that allows trained users to collect samples and develop a model of prediction; the second is the MicroNIR OnSite-W system for real-time prediction of samples and it is suitable even for untrained users.

Calibration of the instrument was obtained prior to the acquisition of the sample, by means of a special accessory that permitted the registration of a dark reference (total absorbance) and a white reference (total reflectance) using Spectralon. The instrumental settings included a nominal spectral resolution of the acquisitions at $6.25 \mathrm{~nm}$ and an integration time of $10 \mathrm{~ms}$, for a total measurement time of $2.5 \mathrm{~s}$ per sample. Chemometric analysis was performed by V-JDSU Unscrambler Lite (Camo software AS, Oslo, Norway). Ten spectra for each sample were collected in order to ensure heterogeneity of the measurement and the mean was considered for the chemometric analysis. The investigation of samples' correlation was first performed by Principal Component Analysis and the models of prediction were developed by the mean of Partial Least Square regression algorithms.

\section{RESULTS AND DISCUSSION}

The feasibility of innovative techniques to address specific issues strictly relies on the standardization of the method on reference samples as representative as possible of those to be processed. To this aim, a reference dataset of samples was considered by processing a number of different kinds of milk, such as cow, goat, and donkey, with different fatty acid contents. In addition, milk specimens after UHT treatments were also included, in order to provide a comprehensive method able to be used for a variety of products. With the aim of avoiding a batch dependent response of the analytical platform, different batches of the same milk and different providers were considered.

Spectra in the NIR region were recorded by the MicroNIR OnSite device, as reported in Figure 1, and chemometric pretreatments were investigated in order to separate samples according to the different types of milk.

Mathematical transformations usually recommended for spectroscopic data (Barnes et al., 1989) were evaluated; in particular, scatter-correction methods were applied, such as Standard Normal Variate transform (SNV) (Geladi et al., 1985), Multiplicative Scatter Correction (MSC), Mean Centering (MC) (Wold and Sjöström, 1977), and normalization (Savitzky and Golay, 1964). In addition, spectral derivation techniques, including Savitzky-Golay (SG) polynomial derivative filters (Rinnan et al., 2009) were considered. Among the investigated spectra pre-treatments, combination of the baseline correction, first derivative transform, and Multiplicative Scatter Correction (MSC) were used to highlight differences among spectra and thus to separate samples according to the different chemical compositions.

Results of the NIR spectra interpretation from Sÿasic and Ozaki (2001) were confirmed, as shown in Figure 2, where the graph of the loadings vs. components PC1 and PC4 is reported.

Therefore, the preliminary Principal Component Analysis performed on the entire dataset of measurements shows a good accordance among samples belonging to the same class (Figure 3) and shows a distribution of the samples as a function of the increasing fatty acid content (Figure 4).

This behavior led us to develop a quantitation model by considering a Partial Least Square Regression algorithm in order to develop a model of predicting milk that permits the rapidly evaluation of its origin and its quality. As required for the validation of analytical methods, all the collected spectra were divided into a training set (about $75 \%$ of samples) and evaluation 


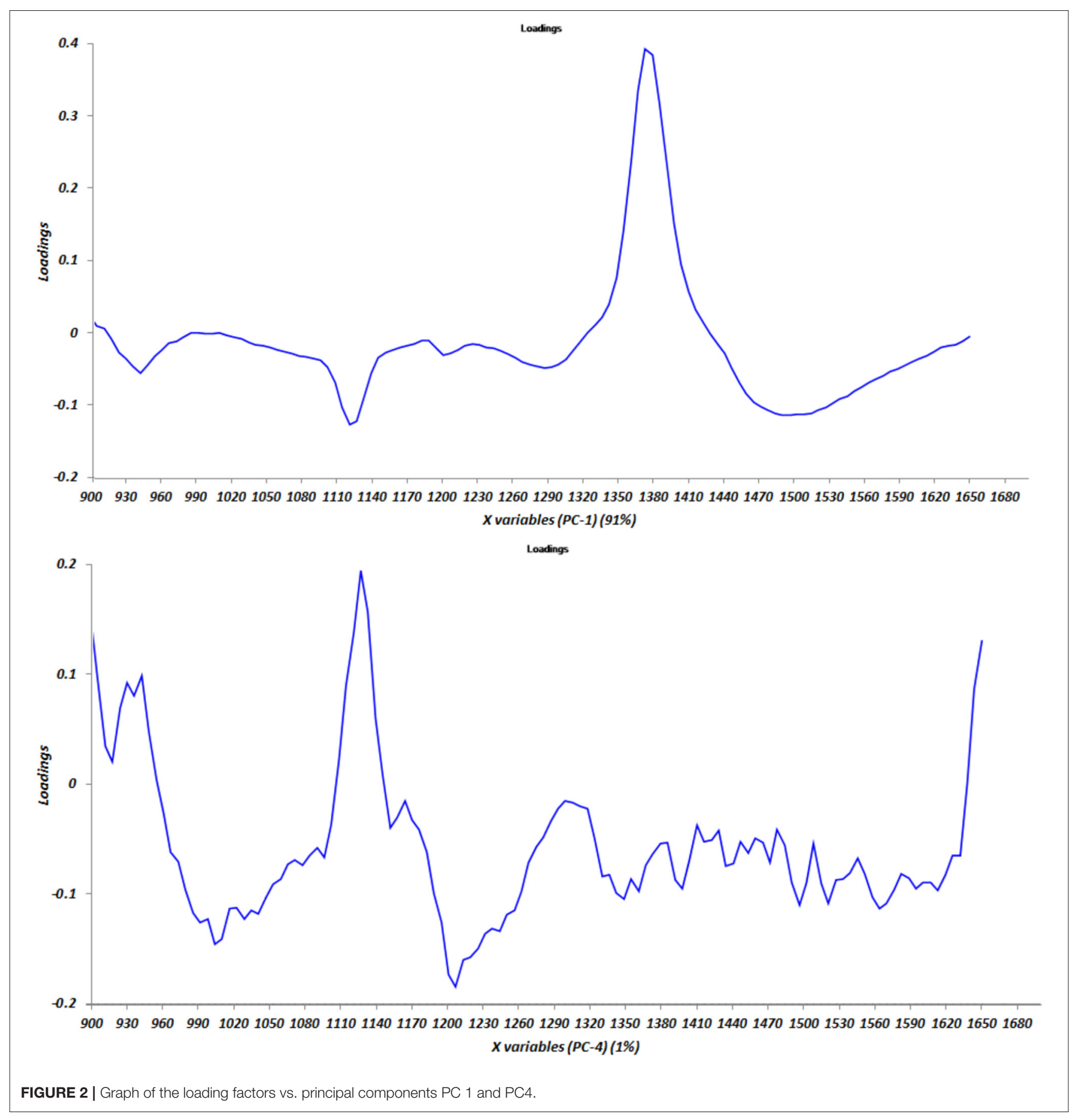

set (about 25\% of samples), and a number of parameters were assessed in order to calculate the model's performances.

Among these, the Root Mean Squared Errors (RMSEs) and the correlation coefficient $\left(\mathrm{R}^{2}\right)$ were estimated in calibration and cross-validation by using seven latent variables, while precision and sensitivity were calculated to provide fast and accurate outcomes when dealing with real samples analysis.
As reported in Figure 5, the model allows users to simultaneously differentiate whole, semi-skimmed, and skimmed milk and to identify the different origins.

As a consequence, the model may recognize the milk quality as a function of the belonging cluster of the spectra and preliminarily addresses the subsequent analyses.

The prediction ability of the model was evaluated by estimating the figures of merit and satisfactory 


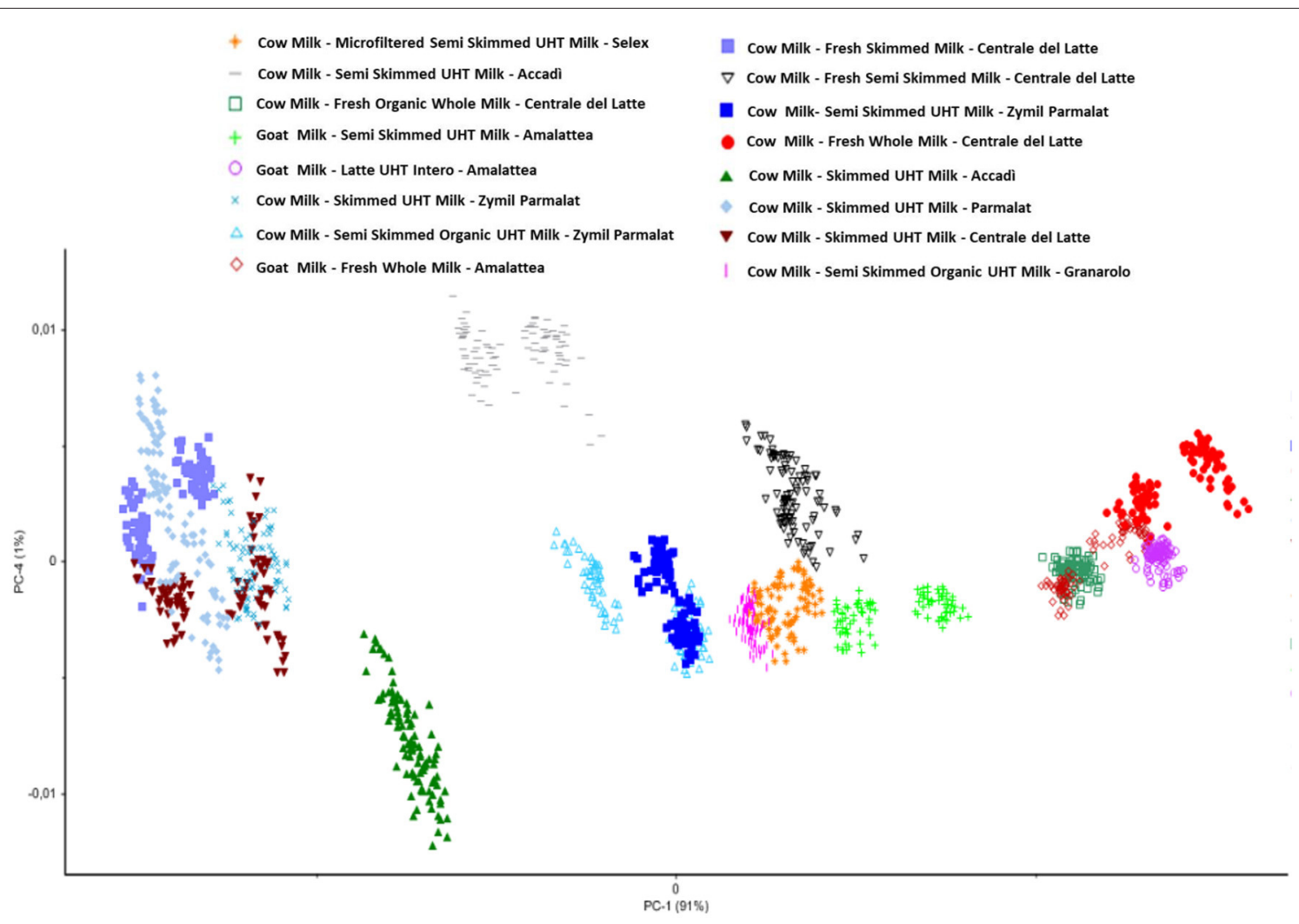

FIGURE 3 | Principal component analysis performed on all the collected samples.

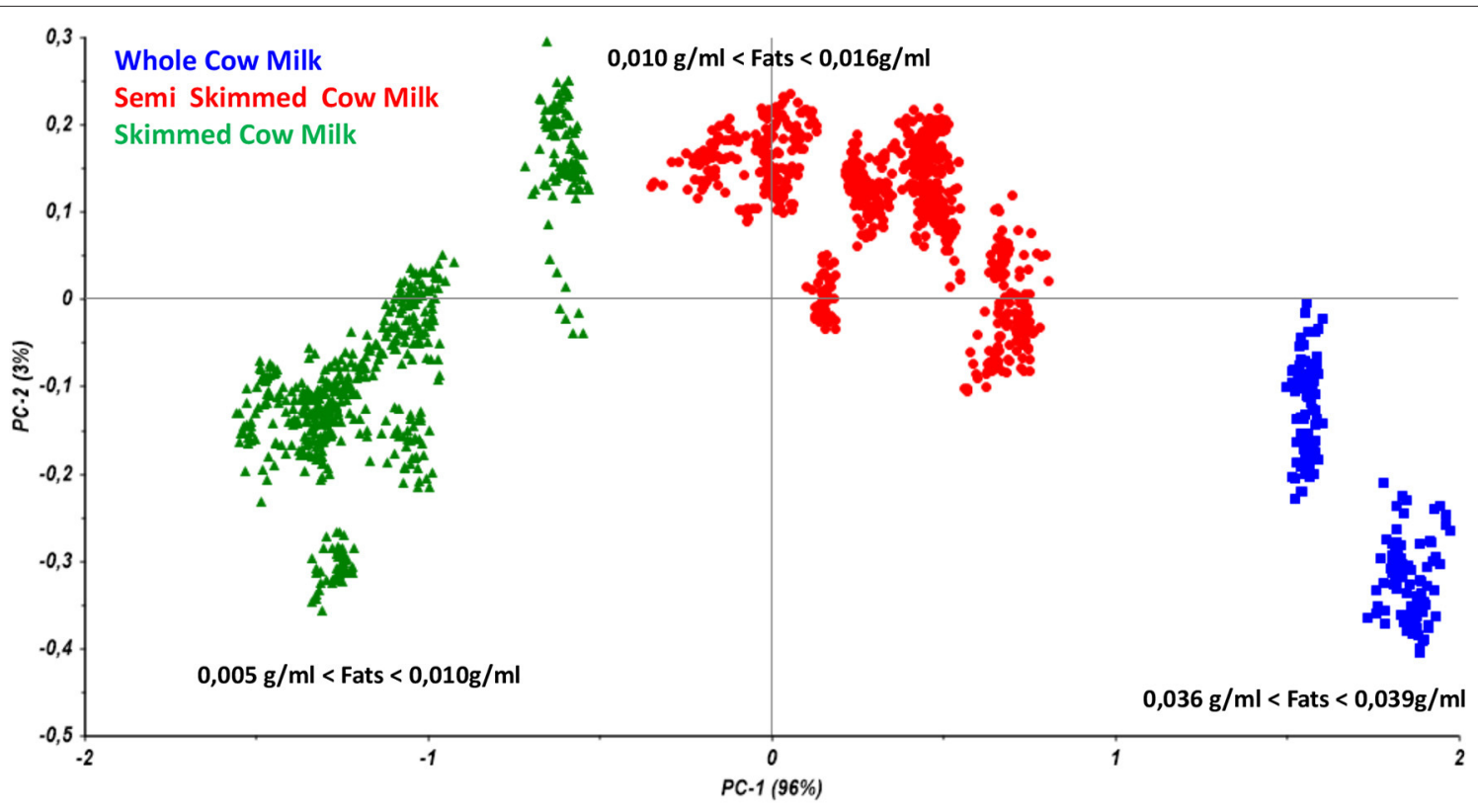

FIGURE 4 | Principal component analysis performed on all the collected samples from cow milk with different fats content.

outcomes may be observed; in fact, the correlation values were never lower than 0.99 in calibration or in cross-validation.
In addition, accuracy, precision, the slope, and the Root Mean Square Error (RMSE) were calculated considering seven latent variables. Results are summarized in Table 2. 


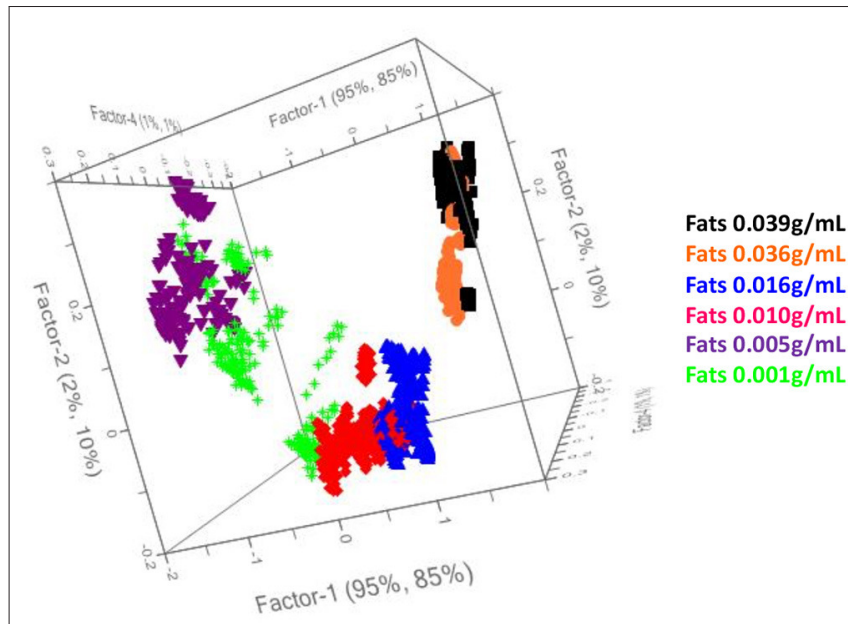

FIGURE 5 | PLS model for fat quantitation in milk specimens.

TABLE 2 | PLS model for milk: estimation of the figures of merit in calibration and cross-validation.

\begin{tabular}{lcc}
\hline & Calibration & Cross-validation \\
\hline Slope & 0.97 & 0.97 \\
$R^{2}$ & 0.099 & 0.98 \\
RMSE $(\mathrm{g} / \mathrm{mL})$ & 0.002 & 0.002 \\
Accuracy $(\%)$ & 98.4 & 97.1 \\
Precision $(\%)$ & 75.3 & 74.6 \\
LVs & 7 & 7 \\
\hline
\end{tabular}

Satisfactory performances of the model may be observed, leading to errors in cross-validation no higher than $0.002 \mathrm{~g} / \mathrm{mL}$ and accuracy values no lower than $97.1 \%$. Precision of the method was also calculated and suitable outcomes were obtained, resulting in precision values about $74.6 \%$.

\section{Feasibility of the Platform}

Prediction of the real samples was performed by processing 17 milk specimens commercially available in the Italian markets, in order to evaluate the platform performances. Samples were analyzed by the MicroNIR On-Site and spectra were processed by the optimized chemometric model. Good accordance among measurements was observed from MicroNIR outcomes, as reported in Table 3. The graph of the measured vs. predicted samples provided for a correlation coefficient of about 0.996 , as all the samples were correctly predicted by the model, confirming the promising application of the platform.

\section{CONCLUSIONS}

In this work, a novel analytical platform based on NIR spectroscopy and chemometrics is proposed for the monitoring of milk quality. The novelty of the platform is strictly related to the innovative MicroNIR On-Site device which can be used to
TABLE 3 | Results obtained from the novel platform for independent real samples.

\begin{tabular}{|c|c|c|c|}
\hline Prediction results & $\begin{array}{l}\text { Fats } \\
(\mathrm{g} / \mathrm{mL})\end{array}$ & Predicted & DS \\
\hline Goat milk-Fresh whole milk-Amalattea & 0.039 & 0.0422 & 0.0002 \\
\hline Goat milk-Latte UHT intero-Amalattea & 0.039 & 0.0372 & 0.0005 \\
\hline $\begin{array}{l}\text { Cow milk-Fresh whole milk-Centrale del } \\
\text { Latte }\end{array}$ & 0.036 & 0.0337 & 0.0003 \\
\hline $\begin{array}{l}\text { Cow milk-Fresh organic whole } \\
\text { milk-Centrale del Latte }\end{array}$ & 0.036 & 0.0331 & 0.0004 \\
\hline $\begin{array}{l}\text { Goat milk-Semi skimmed UHT } \\
\text { milk-Amalattea }\end{array}$ & 0.016 & 0.0178 & 0.0004 \\
\hline $\begin{array}{l}\text { Cow milk-Fresh semi skimmed } \\
\text { milk-Centrale del Latte }\end{array}$ & 0.016 & 0.0130 & 0.0005 \\
\hline $\begin{array}{l}\text { Cow milk-Semi skimmed organic UHT } \\
\text { milk-Granarolo }\end{array}$ & 0.016 & 0.0139 & 0.0004 \\
\hline $\begin{array}{l}\text { Cow milk-Semi skimmed UHT milk-Zymil } \\
\text { Parmalat }\end{array}$ & 0.01 & 0.0083 & 0.0003 \\
\hline $\begin{array}{l}\text { Cow milk-Semi skimmed organic UHT } \\
\text { milk-Zymil Parmalat }\end{array}$ & 0.01 & 0.0089 & 0.0004 \\
\hline $\begin{array}{l}\text { Cow milk-Microfiltered Semi skimmed } \\
\text { UHT milk-Selex }\end{array}$ & 0.01 & 0.0140 & 0.0005 \\
\hline $\begin{array}{l}\text { Cow milk-Semi skimmed UHT } \\
\text { milk-Accadì }\end{array}$ & 0.01 & 0.0084 & 0.0004 \\
\hline UHT Rice milk-Vital Nature & 0.01 & 0.0108 & 0.0004 \\
\hline $\begin{array}{l}\text { Cow milk-Fresh Skimmed milk-Centrale } \\
\text { del Latte }\end{array}$ & 0.005 & 0.0067 & 0.0003 \\
\hline Cow milk-Skimmed UHT milk-Parmalat & 0.005 & 0.0042 & 0.0006 \\
\hline $\begin{array}{l}\text { Cow milk-Skimmed UHT milk-Centrale } \\
\text { del Latte }\end{array}$ & 0.001 & 0.0030 & 0.0003 \\
\hline $\begin{array}{l}\text { Cow milk-Skimmed UHT milk-Zymil } \\
\text { Parmalat }\end{array}$ & 0.001 & 0.0011 & 0.0004 \\
\hline Cow milk-Skimmed UHT milk-Accadì & 0.001 & 0.0032 & 0.0004 \\
\hline
\end{tabular}

collect samples and to perform the prediction in few seconds, even by untrained personnel with an automated platform available on a smartphone. Reliability of this novel test was assessed by processing independent real samples, confirming the feasibility of this novel platform. In addition, the model was validated by estimating the characteristic figures of merit, such as the accuracy, slope, precision, and the RMSE, demonstrating its suitability for application as a screening test for consumers for food monitoring.

\section{DATA AVAILABILITY STATEMENT}

The raw data supporting the conclusions of this article will be made available by the authors, without undue reservation.

\section{AUTHOR CONTRIBUTIONS}

SM and RR conceived the study and interpreted the data by chemometrics and GG performed the analyses. The manuscript was written through contributions of all authors. All authors have given approval to the final version of the manuscript. 


\section{REFERENCES}

Aiello, D., Furia, E., Siciliano, C. Bongiorno, D., and Napoli, A. (2018). Study of the coordination of ortho-tyrosine and trans-4hydroxyproline with aluminum(III) and iron(III). J. Mol. Liq. 269, 387-397. doi: 10.1016/j.molliq.2018.08.074

Aiello, D., Materazzi, S., Risoluti, R., Thangavel, H., Di Donna, L., and Mazzotti, (2015). A major allergen in rainbow trout (Oncorhynchus mykiss): complete sequences of parvalbumin by MALDI tandem mass spectrometry. Mol. Biosyst. 11, 2373-2382. doi: 10.1039/C5MB00148J

Balabin, R. M., and Smirnov, S. V. (2011). Melamine detection by mid- and near-infrared (MIR/NIR) spectroscopy: a quick and sensitive method for dairy products analysis including liquid milk, infant formula, and milk powder. Talanta 85, 562-568. doi: 10.1016/j.talanta.2011.04.026

Barnes, R. J., Dhanoa, M. S., and Lister, S. J. (1989). Standard normal variate transformation and detrending of near-infrared diffuse reflectance spectra. Appl. Spectrosc. 43, 772-777. doi: 10.1366/0003702894202201

Basri, K. N., Hussain, M. N., Bakar, J., Khir, M. F. A., and Zoolfakar, A. S. (2017). Classification and quantification of palm oil adulteration via portable NIR spectroscopy. Spectrochim. Acta Mol. Biomol. Spectrosc. 173, 335-342. doi: 10.1016/j.saa.2016.09.028

Bian, X., Zhang, C., Liu, P., Wei, J., Tan, X., Lin, L., et al. (2017). Rapid identification of milk samples by high and low frequency unfolded partial least squares discriminant analysis combined with near-infrared spectroscopy. Chemom. Intell. Lab. Syst. 170, 96-101. doi: 10.1016/j.chemolab.2017.09.004

Bretti, C., Crea, F., De Stefano, C., Foti, C., Materazzi, S., and Vianelli, G. (2013). Thermodynamic properties of dopamine in aqueous solution. acid-base properties, distribution, and activity coefficients in $\mathrm{NaCl}$ aqueous solutions at different ionic strengths and temperatures. J. Chem. Eng. Data 58, 2835-2847. doi: $10.1021 /$ je400568u

Chotyakul, N., Pateiro-Moure, M., Saraiva, J. A., Torres, J. A., and Pérez-Lamela, C. (2014). Simultaneous HPLC-DAD quantification of vitamins A and E content in raw, pasteurized, and UHT cow's milk and their changes during storage. Eur. Food Res. Technol. 238, 535-547. doi: 10.1007/s00217-013-2130-7

Cossignani, L., Blasi, F., Bosi, A., D’Arco, G., Maurelli, S., Simonetti, M., et al. (2011). Detection of cow milk in donkey milk by chemometric procedures on triacylglycerol stereospecific analysis result. J. Dairy Res. 78, 335-342. doi: $10.1017 /$ S0022029911000495

Crea, F., Falcone, G., Foti, C., Giuffrè, O., and Materazzi, S. (2014). Thermodynamic data for $\mathrm{Pb}^{2+}$ and $\mathrm{Zn}^{2+}$ sequestration by biologically important S-donor ligands, at different temperatures and ionic strengths. New J. Chem. 38, 3973-3983. doi: 10.1039/C4NJ00830H

Cunsolo, V., Saletti, R., Muccilli, V., Gallina, S., Di Francesco, A., and Foti, S. (2017). Proteins and bioactive peptides from donkey milk: the molecular basis for its reduced allergenic properties. Food Res. Int. 99, 41-57. doi: 10.1016/j.foodres.2017.07.002

da Silva, N. C., Cavalcanti, C. J., Honorato, F. A., Amigo, J. M., and Pimentel, M. F. (2017). Standardization from a benchtop to a handheld NIR spectrometer using mathematically mixed NIR spectra to determine fuel quality parameters. Anal. Chim. Acta 954, 32-42. doi: 10.1016/j.aca.2016.12.018

De Angelis Curtis, S., Kurdziel, K., Materazzi, S., and Vecchio, S. (2008). Crystal structure and thermoanalytical study of a manganese(II) complex with 1-allylimidazole. J. Therm. Anal. Calorim.. 92, 109-114. doi: 10.1007/s10973-007-8747-7

D’Elia, V., Montalvo, G., Garca Ruiz, C., Ermolenkov, V. V., Ahmed, Y., and Lednev, I. K. (2018). Ultraviolet resonance Raman spectroscopy for the detection of cocaine in oral fluid. Spectrochim. Acta Mol. Biomol. Spectrosc. 188, 338-340. doi: 10.1016/j.saa.2017.07.010

Dunn, J. D., Gryniewicz-Ruzicka, C. M., Kauffman, J. F., Westenberger, B. J., and Buhse, L. F. (2011). Using a portable ion mobility spectrometer to screen dietary supplements for sibutramine. J. Pharm. Biomed. Anal. 54, 469-474. doi: 10.1016/j.jpba.2010.09.017

Ferreira de Lima, G., Cardoso Andrade, S. A., da Silva, V. H., and Araújo Honorato, F. (2018). Multivariate classification of UHT milk as to the presence of lactose using benchtop and portable NIR spectrometers. Food Anal. Methods 11, 2699-2706. doi: 10.1007/s12161-018-1253-7

Garcia, C., Luts, N. W. Confort-Gouny, S., Cozzone, P. J., Armand, M., and Bernard, M. (2012). Phospholipid fingerprints of milk from different mammalians determined by 31P NMR: towards specific interest in human health. Food Chem. 135, 1777-1783. doi: 10.1016/j.foodchem.2012.05.111

Geladi, P., MacDougall, D., and Martens, H. (1985). Linearization and scattercorrection for near-infrared reflectance spectra of meat. Appl. Spectrosc. 39, 491-500. doi: 10.1366/0003702854248656

Hambraeus, L. (1984). Human milk composition. Nutr. Abstr. Rev. 54, 219-236.

Jankovskà, R., and Šustovà, K. (2003). Analysis of cow milk by near-infrared spectroscopy. Czech J. Food Sci. 21, 123-128. doi: 10.17221/3488-CJFS

Kamboj, U., Kaushal, N., and Jabeen. S. (2020). Near infrared spectroscopy as an efficient tool for the qualitative and quantitative determination of sugar adulteration in milk. J. Phys. Conf. Ser. 1531:012024. doi: 10.1088/1742-6596/1531/1/012024

Kordi, B., Kovacevi, M., Slobod, T., Vidovi, A., and Jovi, B. (2017). FT-IR and NIR spectroscopic investigation of hydrogen bonding in indole-ether systems. J. Mol. Struct. 1144, 159-165. doi: 10.1016/j.molstruc.2017.05.035

Kurdziel, K., Głowiak, T., Materazzi, S., and Jezierska, J. (2003). Crystal structure and physico-chemical properties of cobalt(II) and manganese(II) complexes with imidazole-4-acetate anion. Polyhedron 22, 3123-3128. doi: 10.1016/j.poly.2003.07.004

Mabood, F., Ali, L., Boque, R., Abbas, G., Jabeen, F., Haq, Q. M. I., et al. (2019). Robust Fourier transformed infrared spectroscopy coupled with multivariate methods for detection and quantification of urea adulteration in fresh milk samples. Food Sci. Nutr. 8, 5249-5458. doi: 10.1002/fsn3.987

Marchetti, L., Sabbieti, M. G., Menghi, M., Materazzi, S., Hurley, M. M., Menghi, G. (2002). Effects of phthalate esters on actin cytoskeleton of Pyla rat osteoblasts. Histol. Histopathol. 17, 1061-1066. doi: 10.14670/HH-17.1061

Materazzi, S., Gregori, A., Ripani, L., Apriceno, A., and Risoluti, R. (2017b). Cocaine profiling: Implementation of a predictive model by ATR-FTIR coupled with chemometrics in forensic chemistry. Talanta 166, 328-335. doi: 10.1016/j.talanta.2017.01.045

Materazzi, S., Peluso, G., Ripani, L., and Risoluti, R. (2017c). High-throughput prediction of AKB48 in emerging illicit products by NIR spectroscopy and chemometrics. Microchem. J. 134, 277-283. doi: 10.1016/j.microc.2017.06.014

Materazzi, S., and Risoluti, R. (2014). Evolved gas analysis by mass spectrometry. Appl. Spectrosc. Rev. 49, 635-665. doi: 10.1080/05704928.2014.887021

Materazzi, S., Risoluti, R., Pinci, S., and Romolo, F. S. (2017a). New insights in forensic chemistry: NIR/Chemometrics analysis of toners for questioned documents examination. Talanta 174, 673-678. doi: 10.1016/j.talanta.2017.06.044

Materazzi, S., Vecchio, S., Wo, L. W., and De Angelis Curtis, S. (2012). TG-MS and TG-FTIR studies of imidazole-substituted coordination compounds: Co(II) and Ni(II)-complexes of bis(1-methylimidazol-2-yl)ketone. Thermochim. Acta 543, 183-187. doi: 10.1016/j.tca.2012.05.013

Mees, C., Souard, F., Delported, C., Deconinck, E., Stoffelen, P., Stévigny, C., et al. (2018). Identification of coffee leaves using FT-NIR spectroscopy and SIMCA. Talanta 177, 4-11. doi: 10.1016/j.talanta.2017.09.056

Migliorati, V., Ballirano, P., Gontrani, L., Materazzi, S., Ceccacci, F., and Caminiti, R. (2013). A combined theoretical and experimental study of solid octyl and decylammonium chlorides and of their aqueous solutions. J. Phys. Chem. B 117, 7806-7818. doi: 10.1021/jp403103w

Modrono, S., Soldado, A., Martínez-Fernández, A., and de la Roza Delgado, B. (2017). Handheld NIRS sensors for routine compound feed quality control: real time analysis and field monitoring. Talanta 162, 597-603. doi: 10.1016/j.talanta.2016.10.075

Napoli, A., Aiello, D., Di Donna, L., Prendushi, H., and Sindona, G. (2007). Exploitation of endogenous protease activity in raw mastitic milk by MALDITOF/TOF. Anal. Chem. 79, 5941-5948. doi: 10.1021/ac0704863

Navarra, M.A., Materazzi, S., Panero, S., and Scrosati, B. (2003). PVdF-based membranes for DMFC applications. J. Electrochem. Soc. 150, A1528-A1532. doi: 10.1149/1.1615607

Numthuam, S., Hongpathong, J., Charoensook, R., and Rungchang, S. (2017). Method development for the analysis of total bacterial count in raw milk using near-infrared spectroscopy. J. Food Saf. 37:e12335. doi: 10.1111/jfs.12335

Oliveri, P., Di Egidio, V., Woodcock, T., and Downey, G. (2011). Application of class-modelling techniques to near infrared data for food authentication purposes. Food Chem. 125, 1450-1456. doi: 10.1016/j.foodchem.2010.10.047

Paiva, E. M., Rohwedder, J. J. R., Pasquini, C., Pimentel, M. F., and Pereira, C. F. (2015). Quantification of biodiesel and adulteration with vegetable oils in 
diesel/biodiesel blends using portable near-infrared spectrometer. Fuel 160, 57-63. doi: 10.1016/j.fuel.2015.07.067

Rinnan, A., van den Berg, F., and Engelsen, S. B. (2009). Review of the most common pre-processing techniques for near-infrared spectra. Trends Anal. Chem. 28:10. doi: 10.1016/j.trac.2009.07.007

Risoluti, R., Fabiano, M. A., Gullifa, G., Vecchio Ciprioti, S., and Materazzi, S. (2017). FTIR-evolved gas analysis in recent thermoanalytical investigations. Appl. Spectrosc. Rev. 52, 39-72. doi: 10.1080/05704928.2016.1207658

Risoluti, R., Gregori, A., Schiavone, S., and Materazzi, S. (2018a). "Click and Screen" technology for explosives detection on human hands by portable MicroNIR/Chemometrics platform. Anal. Chem. 90, 4288-4292. doi: 10.1021 /acs.analchem.7b03661

Risoluti, R., Gullifa, G., Battistini, A., and Materazzi, S. (2019b). "Lab-on-click" detection of illicit drugs in oral fluids by microNIR-chemometrics. Anal. Chem. 91, 6435-6439. doi: 10.1021/acs.analchem.9b00197

Risoluti, R., Gullifa, G., Battistini, A., and Materazzi, S. (2019c). MicroNIR/Chemometrics: A new analytical platform for fast and accurate detection of $\Delta 9$-Tetrahydrocannabinol (THC) in oral fluids. Drug Alcohol Depend. 205:107578. doi: 10.1016/j.drugalcdep.2019.107578

Risoluti, R., and Materazzi, S. (2018). MicroNIR/Chemometrics assessement of occupational exposure to hydroxyurea. Front. Chem. 6:228. doi: $10.3389 /$ fchem. 2018.00228

Risoluti, R., Materazzi, S., Tau, F., Russo, A., and Romolo, F. S. (2018b). Towards innovation in paper dating: a MicroNIR analytical platform and chemometrics. Analyst 143, 4394-4399. doi: 10.1039/C8AN00871J

Risoluti, R., Piazzese, D., Napoli, A., and Materazzi, S. (2016). Study of [2-(2'-pyridyl)imidazole] complexes to confirm two main characteristic thermoanalytical behaviors of transition metal complexes based on imidazole derivatives. J. Anal. Appl. Pyrol. 117, 82-87. doi: 10.1016/j.jaap.2015.11.018

Risoluti, R., Pichini, S., Pacifici, R., and Materazzi, S. (2019a). Miniaturized analytical platform for cocaine detection in oral fluids by MicroNIR/Chemometrics. Talanta 202, 546-553. doi: $10.1016 /$ j.talanta.2019.04.081

Rocchetti, G., Gallo, A., Nocetti, M., Lucini, L., and Masoero, F. (2020). Milk metabolomics based on ultra-high-performance liquid chromatography coupled with quadrupole time-of-flight mass spectrometry to discriminate different cows feeding regimens. Food Res. Int. 134:109279. doi: $10.1016 /$ j.foodres.2020.109279

Saha, D., and Thangavel, K. (2018). Rapid detection of formalin in milk by Fourier-transform Near-infrared spectroscopy. J. Agric. Res. 55, 772-774. doi: 10.5958/2395-146X.2018.00143.6

Santos, M. P., Pereira-Filhos, E. R., and Colnago, L. A. (2016). Detection and quantification of milk adulteration using time domain nuclear magnetic resonance (TD-NMR). Microchem. J. 124, 15-19. doi: 10.1016/j.microc.2015.07.013

Savitzky, M. J., and Golay, E. (1964). Smoothing and differentiation of data by simplified least squares procedures. Anal. Chem. 36, 1627-1639. doi: $10.1021 / \mathrm{ac} 60214 \mathrm{a} 047$

Soulat, J., Andueza, D., Graulet, B., Girard, C. L., Labonne, C., Aït-Kaddour, A., et al. (2020). Comparison of the potential abilities of three spectroscopy methods: near-infrared, mid-infrared, and molecular fluorescence, to predict carotenoid, vitamin and fatty acid contents in cow milk. Foods 9:592. doi: $10.3390 /$ foods 9050592

Sÿasic, S., and Ozaki, Y. (2001). Short-wave near-infrared spectroscopy of biological fluids. Quantitative analysis of fat, protein, and lactose in raw milk by partial least-squares regression and band assignment. Anal. Chem. 73, 64-71. doi: $10.1021 /$ ac000469c

Teng, F., Wang, P., Yang, L., Ma, Y., and Day, L. (2017). Quantification of fatty acids in human, cow, buffalo, goat, yak, and camel milk using an improved one-step GC-FID method. Food Anal. Methods 10, 2881-2891. doi: $10.1007 / \mathrm{s} 12161-017-0852-\mathrm{z}$

Véstia, J., Barros, J. M., Ferreira, H., Gaspar, L., and Rato, A.E. (2019). Predicting calcium in grape must and base wine by FT-NIR spectroscopy. Food Chem. 276, 71-76. doi: 10.1016/j.foodchem.2018.09.116

Wang, Y., Guo, W., Zhu, X., and Liu, Q. (2019). Effect of homogenisation on detection of milk protein content based on NIR diffuse reflectance spectroscopy. Int. J. Food Sci. Technol. 54, 387-395. doi: 10.1111/ijfs.13948

Wold, S., and Sjöström, M. (1977). Chemometrics: theory and applications. Am. Chem. Soc. Symp. Series 52, 243-282. doi: 10.1021/bk-1977-0052.ch012

Zhou, Q., Gao, B., Zhang, X., Xu, Y., Shi, H., and Yu, L. (2014). Chemical profiling of triacylglycerols and diacylglycerols in cow milk fat by ultra-performance convergence chromatography combined with a quadrupole time-of-flight mass spectrometry. Food Chem. 143, 199-204. doi: 10.1016/j.foodchem.2013. 07.114

Conflict of Interest: The authors declare that the research was conducted in the absence of any commercial or financial relationships that could be construed as a potential conflict of interest.

Copyright $\odot 2020$ Risoluti, Gullifa and Materazi. This is an open-access article distributed under the terms of the Creative Commons Attribution License (CC BY).

The use, distribution or reproduction in other forums is permitted, provided the original author(s) and the copyright owner(s) are credited and that the original publication in this journal is cited, in accordance with accepted academic practice. No use, distribution or reproduction is permitted which does not comply with these terms. 